\title{
A neo-institutionalist model of the diffusion of IFRS accounting standards
}

\author{
Dominique Dufour (corresponding author) ${ }^{1}$, Pierre Teller ${ }^{2}$, Philippe Luu ${ }^{3}$ \\ ${ }^{1}$ Assistant professor, Nice-Sophia Antipolis University, GRM EA 471, \\ domduf@wanadoo.fr \\ ${ }^{2}$ Assistant professor, Nice-Sophia Antipolis University, GRM EA 471, \\ pierre.teller@unice.fr \\ ${ }^{3}$ Statistical engineer, Nice-Sophia Antipolis University, GRM EA 4711, \\ philippe.luu@unice.fr
}

\begin{abstract}
The purpose of this study is to prepare a diffusion model of the new international accounting standards known as the IFRS (International Financial Reporting Standards). This model fits within the neo-institutional conceptual framework; more specifically, we used the DiMaggio/Powell analytical grid.
\end{abstract}

Our desire to prepare this model was born from the observation that the analytical framework that is generally used to study the adoption of these new standards is the neoinstitutional framework and that the principal methodologies implemented are qualitative. The question addressed in this study regards the forces leading an agent - in this case, an organisation providing standards for accounting - to adopt, at a given moment, these new standards. Existing studies, as interesting as they might be, are devoted to the question of adoption and leave aside the question of diffusion. In other words, the evolution of the system as a whole in time is ignored. Constructing a model appeared to us to be a way to move beyond these limitations.

This model allows us to formalise the forces at work in the DiMaggio/Powell representation and to simulate the diffusion processes of the IFRS. To this end, we implement a multi-agent simulation. The various simulation scenarios are then compared to the observed diffusion of the IFRS.

Keywords: IFRS, diffusion, neo-institutionalism, multi-agent simulation. 


\section{Introduction}

The International Accounting Standards Board (IASB) is a private organisation whose mission is the development and promotion of international accounting standards: the IFRS (International Financial Reporting Standards) (Chiapello and Medjad, 2009). In 2002, the European Community adopted a regulation (EC Regulation no. 1606/2002 of 19 July 2002) that aimed to replace the many national accounting standards with a single standard (the IFRS). Within the European Union, these new standards primarily affect listed companies. The first financial statements that have been presented with the use of these standards are the consolidated financial statements for the year ended January 1, 2005. After this date, the number of countries adopting these norms has continued to increase (Chua and Taylor, 2008).

The theoretical framework on which our work is based is the neoinstitutionalist framework defined by DiMaggio and Powell in 1983 (DiMaggio and Powell, 1983). These authors reflect on the forces that push organisational structures to become homogeneous. According to DiMaggio and Powell, three forces (which the authors call isomorphisms) contribute over time to this homogenisation: mimetic, coercive, and normative isomorphisms. This theoretical framework has been used various times to study the adoption mechanisms of new accounting standards and practices, with the aid of articles that draw, above all, on case studies but also sometimes on quantitative approaches.

These articles appear to us to have various limitations. The first limitation is that they are devoted more to the study of the punctual adoption of the new standards rather than to its diffusion. The second limitation more particularly concerns the studies' use of quantitative approaches. The forces defined by DiMaggio and Powell are approximated with the use of variables that describe the individual characteristics of the agents rather than the nature of the forces to which these agents are subjected. The third limitation concerns the case studies. Because these case studies analyse adoption in a specific context, it is difficult to generalise their conclusions. More generally, neither the case studies nor the quantitative studies take into account the interactions between agents, interactions that are at the heart of DiMaggio and Powell's representation.

The objective of this paper is the construction of a multi-agent model that can simulate the diffusion of the new international accounting standards, the IFRS standards (International Financial Reporting Standards).

This model was elaborated to allow for the implementation of a numerical simulation whose function is to represent the phenomenon of the diffusion of new standards over time. This diffusion - which, in fact, takes the form of a convergence toward a single system - should be analysed from a dynamic perspective. At moment $t$, the result of the 
interaction of isomorphic forces is likely to lead the agent to adopt the new standards, the agent here being a country (we use the word "country" as a matter of convenience - in fact, the choice of agent is the accounting standards organisation's). This adoption, in turn, modifies the environment and thus the nature of the forces that will be operating at moment $t+1$. This model is one of the major contributions of our study, in contrast with other studies devoted to this question, which analyse adoption and not diffusion. The numerical simulation offers the opportunity to observe the evolution of this phenomenon modelled over a large number of periods (the period representing a given time interval, such as a fiscal or calendar year). By having uniquely represented instantaneous mechanisms of adoption at the initial moment, the simulation allows the investigator to see the temporal dynamics of diffusion unfold. Diffusion, which is the general adoption of the IFRS, is studied based on the study of adoption, which is the choice made by an agent to use these new accounting standards.

To our knowledge, there are no prior academic studies that have implemented a multi-agent modelling and numerical simulation in this context.

Modelling is a crucial step in this process and should, in fact, allow the elaboration - based on the conceptual framework used - of a set of algorithms that allow numerical simulations to be performed with the aid of a computer. Here, modelling consists of a system of equations that represent the coercive, mimetic, and normative forces of the neoinstitutional framework. The simulation is then run a large number of times, and the various parameters of the equations of our model are varied according to several scenarios. This simulation produces what we refer to as the generated data.

The final step is the validation of the model. First, the generated data are compared to the real data (that is, the observed adoption of the IFRS over thirteen years). We use a Kolmogorov-Smirnov (K-S) test to compare the average distribution of each of the scenarios to the real distribution. The K-S test is a test for goodness of fit to a continuous law. This nonparametric test can be used to determine if a sample has a good fit to a given law or if two samples follow the same law. In our study, we made use of the K-S test to compare between two distributions (simulated distribution vs. real distribution). The comparison between the generated data and the observed data was productive. On the one hand, it appears that some simulated data are close to the observed data, proof of the quality of the model calibration. On the other hand, the examination of the scenarios leading to the generated data that are closest to the observed data elucidates the determining influence of coercive and normative forces. This type of observation has already been highlighted in case studies that are devoted to adoption and within the neo-institutionalist approach.

The contribution of this paper is to allow for a formalisation of the neo-institutionalist approach even though the authors who use this framework ordinarily use qualitative approaches. This formalisation has 
the advantage of allowing the study of the process of diffusion, which is to say, the development of the adoption of the new standards. As far as we know, this is the first time that a study of this type has been conducted.

This article is constructed as follows. In the development that follows, we present the conceptual framework that is used, and in the following section, we describe our proposed model. The methodology of the multi-agent simulation is then presented. Next, the results as well as their applications are summarised. Finally, we present our conclusions.

\section{Conceptual framework}

In this discussion, we briefly present the DiMaggio/Powell grid within which our work fits. The analytical grid suggested by DiMaggio and Powell is regularly used to study accounting choices (DiMaggio and Powell, 1983). We restricted ourselves to the use of this grid, without taking into account more recent developments within the neo-institutionalist approach because this grid appeared to suffice for the elaboration of a multi-agent simulation to test our model.

DiMaggio and Powell studied the tendency of organisational structures to become uniform. They highlight the concept of isomorphism, within which they distinguish two forms, competitive and institutional: "The concept that best captures the process of homogenization is isomorphism. In Hawley's (1968) description, isomorphism is a constraining process that forces one unit in a population to resemble other units that face the same set of environmental conditions" (DiMaggio and Powell, 1983 p. 149). In the remainder of DiMaggio and Powell's work, they focus on institutional isomorphism, the implementation of which rests on three mechanisms: "We identify three mechanisms through which institutional isomorphic change occurs, each with its own antecedents: 1) coercive isomorphism that stems from political influence and the problem of legitimacy; 2) mimetic isomorphism resulting from standard responses to uncertainty; and 3) normative isomorphism, associated with professionalization" (DiMaggio and Powell 1983, p. 150). Coercive isomorphism has its origin in the formal and informal pressures that an organisation experiences from other organisations upon which it is dependent as well as pressures to conform to the values of the environment. Mimetic isomorphism is a response to uncertainty: in an uncertain situation, the organisation can decide that it is easier to copy the practices of the neighbouring organisations. Finally, normative isomorphism originates in the professional practices of the managers in charge of the organisations: the managers receive identical training and propagate the values from this training within organisations.

The accounting choices of public or semi-public organisations have been studied with the aid of this grid: the use of new management tools (Hoque and Adams, 2011); choices by municipalities (Collin et al., 2009); choices by local governments (Caccia and Steccolini, 2006); choices by hospitals (Jarvinen, 2006); the transition to accounting on an accrual basis 
by a state (Baker and Rennie, 2006); and the practices of national standards organisations (Carpenter et al., 2001; Mir and Ramahan, 2005; Irvine, 2008; and Judge et al., 2010). Accounting choices have also been studied for company accounting practices: practices having to do with management accounting (Tsamenyi et al., 2006) and the application of foreign standards by a local company (Touron, 2005).

Various methods can be used to implement this grid. Case studies have been be used (Carpenter et al 2001; Touron, 2005; Caccia and Steccolini, 2006; Baker and Rennie, 2006; Tsamenyi et al., 2006; Hoque and Adams, 2011; Jarvinen, 2011; and Albu et al., 2011). In this approach, one or various entity (-ties) - a company or other organisations - is (are) analysed, chiefly by using interviews as well as by the analysis of internal documents. For their study, Hoque and Adams used questionnaires (Hoque and Adams, 2011). Interviews allow the protagonists to report on the isomorphic forces to which their organisation has been exposed.

It is also possible to make use of the more traditional statistical tools, among which regression takes a leading role. The dependent variable is adoption when the explanatory variables are drawn from the neoinstitutional framework of analysis (Collin et al., 2009; Judge et al., 2010; and Lasmin et al., 2011). We can cite the following explanatory variables: level of foreign aid, weight of imports, and level of education in the study by Judge et al.; and foreign aid, market capitalisation, level of education, foreign investments, and GDP in the study by Lasmin.

As interesting as they might be, these approaches have some limitations. Case studies are difficult to generalise. Case studies are confined to the analysis of specific situations and do not allow the generalisation of accounting practices to be analysed. Case studies can reveal forces at work in a particular context, forces that might be absent in another context.

The use of quantitative methods leads to a difficulty of a different kind: the use of proxies allows for the integration of isomorphic forces as explanatory variables. One can question the ability of these proxies to satisfactorily describe the forces defined by DiMaggio and Powell.

Regardless of the type of approach used, it is always adoption that is being studied. This singular focus is another limitation of these approaches. The mechanism of convergence - which is at the heart of DiMaggio and Powell's representation - is thus ignored because the dynamics of the adoption are not taken into account.

Wishing to go beyond these limitations, we elaborated a model whose intention is twofold: to formalise the isomorphic forces and to represent the dynamics of the diffusion. 


\section{Model: equations and parameters}

Our simulation model is based first of all on the creation of equations describing the isomorphic forces whose combination is likely to lead an agent to adopt the IFRS. We then defined the thresholds of adoption to include this study within the chosen field: the development of the IFRS.

\subsection{The equations and isomorphisms of DiMaggio and Powell}

The formalisation of isomorphic forces revealed itself to be the crucial step in this study. We use the general framework defined by DiMaggio and Powell while, to formalise these forces, we rely on the results of the studies devoted to the process of diffusion.

The simulation that we constructed uses the three isomorphisms defined by DiMaggio and Powell: coercive isomorphism, mimetic isomorphism, and normative isomorphism.

The forces of coercive isomorphism are forces produced by other agents, on the one hand, and by the environment, on the other hand: "Coercive isomorphism results from both formal and informal pressures exerted on organizations by other organizations upon which they are dependent and by cultural expectations in the society within which organizations function" (Di Maggio and Powell, 1983, p. 150).

We note that coercive isomorphism is applied in a homogenous manner for each agent and depends only on time.

The equation describing the influence of coercive isomorphism on the change in accounting standards is the following:

$$
\begin{gathered}
\left.c(t+1)=\sigma\left(c(t)+i_{\gamma} *(100-c(t))\right)+(1-\sigma)\right)\left(\frac{\sum_{j} 1_{I F R S, j}(t)}{N} * 100\right\} \\
\forall i \in \text { population, } c_{i}(t)=c(t) \in[0,100]
\end{gathered}
$$

In this equation

- $i_{\gamma}$ is a parameter indicating the intensity of the influence of the environment on the agents. $i_{\gamma}$ ranges between 0 (no influence) and 1 (maximum influence);

- $\sigma$ is the weighting of the environmental influence in coercive isomorphism. The other component of this isomorphism, the influence of the other agents, consequently, has a weighting of 1$\sigma$. Because this is a weighting, $\sigma$ has a value of between 0 and 1 ; 
- $\quad N$ is the number of countries;

- $\quad \forall j \in$ population,

$$
1_{\text {IFRS }, j}(t)=\left\{\begin{array}{c}
1 \text { if the agent adopted IFRS at moment } t \\
0 \text { if it did not adopt IFRS at moment } t
\end{array}\right.
$$

This formulation is faithful to the content assigned by DiMaggio and Powell. The influence of the environment is described by the first term on the right of the equation. A term written as $i_{\gamma}$ is introduced to simulate the different intensities of this influence. Except for the case when the value 0 is assigned for $i_{\gamma}$, the coercive force engendered by the environment - measured by the first term on the right of the equation increases over time.

The influence of the other agents - described by the second term on the right of the equation - is a function of the number of agents that have adopted the standards. The higher this term is, the greater the legitimacy of the standards' adoption. Here, as well, the coercive force increases over time.

In accounting studies using the framework defined by DiMaggio and Powell, the forces defining coercive isomorphism are the following: the World Bank and the IMF (Mir and Rahaman, 2005, Irvine, 2008, Albu et al., 2011), the financial markets (Albu, 2011), and large international companies (Irvine, 2008). The objective of an organisation in aligning itself with the practices encouraged by these forces is thus to acquire legitimacy.

A mimetic behaviour is a behaviour that consists of reproducing the practices of another organisation. The fact that an organisation can experience difficulties in evaluating the impact of an innovation or the existence of uncertainty regarding an innovation's benefits is a cause of this mimesis: "When organizational technologies are poorly understood, when goals are ambiguous, or when the environment creates symbolic uncertainty, organizations may model themselves on other organizations" (Di Maggio and Powell, 1983, p 150).

The equation describing the influence of mimetic isomorphism on the change in accounting standards is the following:

$$
\begin{gathered}
m_{i}(t)=\underbrace{\frac{\sum_{j \in V} v_{j} 1_{\text {IFRS }, j}(t)}{\sum_{j \in V} v_{j}}}_{\text {uncertainty }} * \tau(t) \\
\forall i \in \text { population }, m_{i}(t) \in[0,100]
\end{gathered}
$$


We note that the influence of other agents is in this case limited to the vicinity around the agent that undergoes mimetic isomorphism, which is written as $V$. This limitation allows for more weight to be given to an agent if it is closer and also allows the influence on mimetic isomorphism from some agents to be eliminated if the agents are considered to be too distant.

The agents in our network are divided into a grid in which the position of each is defined by its $X$ and $Y$ coordinates. To calculate the distance between agents $A\left(x_{1}, y_{1}\right)$ and $B\left(x_{2}, y_{2}\right)$, we used $d(A, B)=\max \left(\mid x_{2}-\right.$ $\left.x_{1}|,| y_{2}-y_{1} \mid\right)$. In figure 1 , we represent the set of agents making up the vicinity of agent with coordinates $(4,5)$. In this example, the maximum distance for inclusion in the vicinity is 2 .

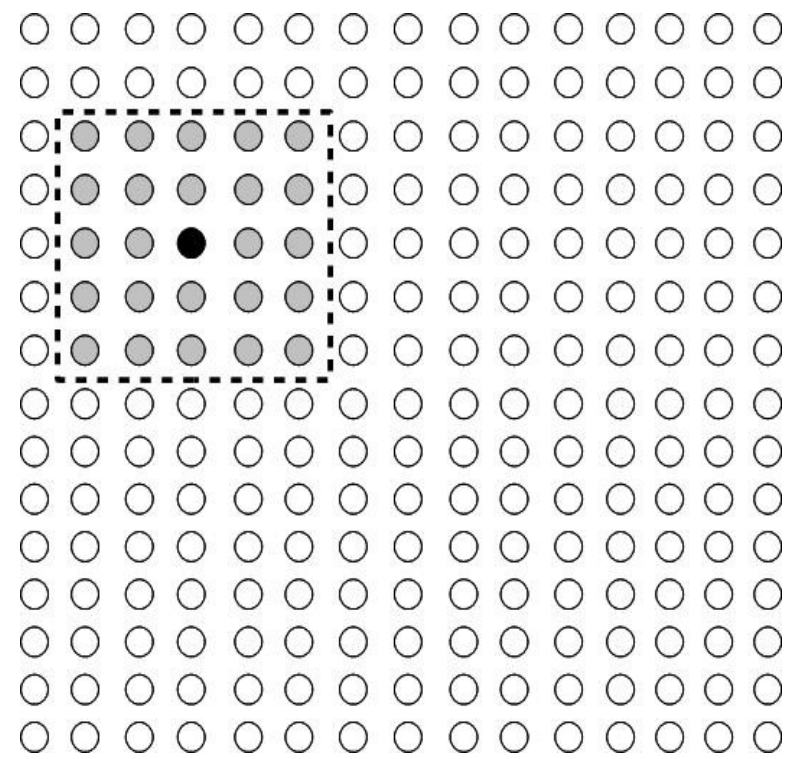

Figure 1: The structure of the network of agents and the definition of the concept of vicinity

The coefficients written as $v_{j}$ represent the weights associated with the influence of the agents as a function of their distance. These weights are always positive or null, but the more distant an agent is, the weaker its associated weight in the above formula will be.

The final element to be introduced into this formula is uncertainty. To conform to the theoretical framework, we introduced a function that is positive and decreases over time. Here is how we have represented uncertainty, $\tau(t)$ :

$$
\tau(t)=\omega+\frac{1}{t} \quad \text { with } \quad 0 \leq \omega \leq 1 \quad \text { and } \quad \lim _{t \rightarrow \infty} \tau(t)=\omega
$$

Mimetic isomorphism is stronger

- when the neighbouring organisations are similar and

- when there exists uncertainty with regard to the benefits of change. 
The first term is a constant - it describes the state of the vicinity. The second term allows uncertainty to be taken into account. The combination of the two engenders sensitivity to mimetic isomorphism. Over time, the knowledge of the contributions and the limitations of the adoption of IFRS should increase; to put it another way, in the simulations that we conducted, uncertainty always decreases over time. This result does not mean that mimetic force must necessarily decrease because the first part of the equation (influence of vicinity) is set to increase.

Mimetic isomorphism principally represents the influence of the vicinity in which an agent seeks to gather information. We also considered that the weight of a neighbour diminishes with distance. In the studies devoted to adoption, mimetic isomorphism originates in the existence of commercial partners (Irvine, 2008 and Judge, 2005) as well as in the influence of neighbouring countries. Mimetic isomorphism is thus the influence of the near vicinity on national practices.

Normative isomorphism is a consequence of what DiMaggio and Powell call "professionalization". They write: "A third source of isomorphic organizational change is normative and stems primarily from professionalization. We interpret professionalization as the collective struggle of members of an occupation to define the conditions and methods of their work, to control the production of producers, and to establish a cognitive base and legitimation for their occupational autonomy" (Di Maggio and Powell, 1983 p 151). The equation describing the influence of normative isomorphism on a change in accounting standards is the following:

$$
\begin{aligned}
& \forall i, n_{i}(t+1)=n_{i}(t)+\rho *\left(100-n_{i}(t)\right) \\
& \forall i \in \text { population }, n_{i}(t) \in[0,100]
\end{aligned}
$$

where $\rho$ is a constant coefficient representing the speed of growth of normative isomorphism. $\rho$ ranges between 0 and 1 .

Once again, we have defined this equation in reference to the work of DiMaggio and Powell. They write: "Two aspects of professionalization are important sources of isomorphism. One is the resting of formal education and of legitimation in a cognitive base produced by university specialists; the second is the growth and elaboration of professional networks that span organizations and across which new models diffuse rapidly" (DiMaggio and Powell, 1983, p. 152).

The establishment of this professional network takes time. The influence that this network exerts on an agent is its own, in contrast to coercive pressure, which is global and common in intensity for all of the agents in the simulation. There are thus differences in normative 
isomorphism between countries, justified by the fact that the levels of training for members of the accounting profession are not the same everywhere. For this reason, normative pressure is not uniform. Normative pressure varies as a function of time but is always increasing as time passes. In the case of the IFRS, accounting companies are the agents for this professionalisation (Mir and Rahaman, 2005, Irvine, 2008, and Albu et al., 2011). The weight of the large international accounting companies has continued to become more significant in recent years. Their influence is twofold. Their influence is drawn from the establishment of the IFRS on the one hand and the conditions of its implementation on the other.

Figure 2 summarises the way in which each isomorphism works on each agent.

Figure 2: The influence of the three types of isomorphism on agents at moment $t$

\subsection{Thresholds and conditions for reform}

The basic unit of the model is the agent. The agent is subjected to the combination of three forces - described by the equations - 
encouraging it to adopt the IFRS. We hypothesised that adoption can only take place if the coercive isomorphism or normative isomorphism exceeds a given threshold. In choosing not to provide a threshold for mimetic isomorphism, we wanted to take into account the fact that the mimetic force cannot trigger adoption on its own. We thus avoid a situation where an agent adopts the standards without undergoing a strong coercive or normative pressure. The finding that transition cannot take place without sufficient action from normative or coercive isomorphism is coherent with the conclusions of Mir and Rahaman (2005), Irvine (2008), and Albu et al. (2011).

For agent $i$ at the moment $t$, we define a window of adoption $F A_{i}(t)$ as follows:

$$
F A_{i}(t)=\left(n_{i}(t)>\text { threshold }_{n}\right) \cup\left(c(t)>\text { threshold }_{c}\right)
$$

where $n$ represents normative isomorphism, $c$ represents coercive isomorphism, and threshold $_{n}$ and threshold ${ }_{c}$ are the values to be surpassed to open a window of adoption. The moment $t$ represents an iteration number in the current simulation.

If at moment $t$, the window of adoption for the agent is open ( $F A_{i}(t)=$ true $)$, then agent $i$ adopts the IFRS with a probability $P_{i}(t)$ as follows:

$$
P_{i}(t)=\frac{1}{100} *\left(\frac{1}{3}\left(c(t)+m_{i}(t)+n_{i}(t)\right)\right)
$$

where $m$ represents the mimetic isomorphism.

We note that in their study, DiMaggio and Powell do not give a special place to any of these three forces. We thus have attributed the same weight to the three isomorphic forces.

The three isomorphic forces can take values ranging from 0 to 100 . To produce a value for a probability ranging between 0 and 1 , we therefore divided the average of the isomorphisms by 100. In other words, if the window of an agent is open at moment $t$, adoption is a random variable distributed according to a Bernoulli law of probability $P_{i}(t)$.

\section{Principle of numerical simulation}

Numerical simulation appeared to us to be a particularly appropriate methodology for this study. Numerical simulation can be defined as: "[...] a method for using computer software to model the operation of "real world" processes, systems, or events" (Davis et al., 2007, p. 481). There are various families of numerical simulations; in this study, we use the type of simulation known as an agent or a multi-agent simulation. Although this tool was developed within the context of management sciences, it is less 
frequently used in this domain than in other domains such as economics, biology, or psychology. Nevertheless, the management science domains of marketing (Rand and Rust, 2011), logistics (Fournier et al., 2010), or even the diffusion of innovation and social networks (Wang et al., 2009) make use of this method.

The literature indicates various possible uses of simulation methods. In a reflection on the use of these methods in the management sciences (Davis et al., 2007), it is mentioned that simulation is especially interesting when it is used for studies that involve theoretical constructions (extracted from case studies, Eisenhardt, 1989), formal modelling (Freese, 1980), and theoretical validations based on the use of descriptive statistics (Pfeffer, 1993).

This study is based on a multi-agent simulation. This methodology lends itself particularly well to our work. Our model was constructed to allow us to observe the interactions in a network of agents, which are the national organisations for accounting standards, and we have modelled the individual behaviour of these agents. The program will then simulate the individual behaviour of each agent and its interactions with the other agents (while also taking into account the more general influence of the environment, notably through coercive isomorphism). The result of this process can be to cause the agents to abandon their local accounting standards and adopt the IFRS. This result has consequences for the agent (i.e., adoption of the IFRS) but also for other countries because by modifying the characteristics of the network, this choice affects the forces that are likely to lead to adoption of the IFRS by the other agents. This process is repeated several times to cause the various possible global evolutions for our network to emerge (Garcia, 2005).

These characteristics of our model mean that the multi-agent simulation was particularly appropriate for our needs, whether for observing the emergence of global behaviour based on a multitude of individual behaviours, for observing a dynamic of diffusion over time, or for capturing the reciprocity of influence between agents and the environment. These dimensions would be difficult to observe with other more classic methodologies.

This simulation makes use of parameters that are likely to take on various values, which allows the various states or configurations of the modelled phenomenon (or, as we will say below, the various scenarios) to be represented. This simulation is coded in the form of a computer program. The execution of this program allows, by varying the set of parameters, the production of data that will allow the development of our network to be observed over time. In other words, it is an experimental method in which the results are not observed, but produced. To do this, the simulation is repeated various times, whether by varying the parameters of the model to study the respective influences of the different parameters or by preserving the same values to work on the average of the results and thus to limit the influence of aberrant or extreme values when there are random results. 


\section{Calibration of the model}

We present here the results of our simulations. The model was constructed to simulate the diffusion of the IFRS. First, we describe the simulation that we ran and the set of associated parameters. Second, we compare the data generated by the simulation with the collected data. This stage of the study allowed us to identify the simulations (or rather, the set of parameters) that can best approach the real data. Finally, the study of the parameters allows us to draw conclusions regarding the predominating forces in diffusion.

\subsection{The initial values and the choice of parameters}

To run the simulation, we needed to define two initial values: the initial value measuring the influence of the other agents in the case of coercive isomorphism. This value depends on the number of first adopters. We defined this value at five agents;

the initial normative value to which an agent is subjected. This value is drawn by chance according to a uniform law ranging between 0 and 1.

Our simulation is constructed with a network of 225 agents, which we can represent by a $15 \times 15$ square grid. The goal is to evaluate how the interaction between agents globally affects the adoption of the standards.

With our equations, the three isomorphisms are likely to take multiple forms. To limit the number of scenarios, we have limited the number of values that are likely to be taken by the parameters. These values are indicated in table 1.

Within coercive isomorphism, an equilibrium between the exterior pressure and the internal pressure can also exist. Likewise, only one of these components might be present. In the coercive process as well, external pressure can grow or fluctuate over time. The influence of the normative force with various speeds of professionalisation was tested. With respect to mimetic isomorphism, the different degrees of vicinity were considered. Finally, the thresholds for opening a window of adoption can have a level that is more or less elevated. 
Table 1: List of the different scenarios

\begin{tabular}{|c|c|c|c|c|}
\hline $\begin{array}{l}\text { Type of } \\
\text { isomorphism }\end{array}$ & Parameter & $\begin{array}{l}\text { Possible } \\
\text { value }\end{array}$ & Description & $\begin{array}{l}\text { Values used } \\
\text { in the } \\
\text { simulation }\end{array}$ \\
\hline \multirow{3}{*}{ Coercive } & $\sigma$ & $0-1$ & $\begin{array}{l}\text { Determines the } \\
\text { equilibrium of } \\
\text { weight between } \\
\text { internal and } \\
\text { external pressure }\end{array}$ & $0 ; 0.5 ; 1$ \\
\hline & $i_{\gamma}$ & $\begin{array}{l}\text { fluctuating } \\
\text { / growing }\end{array}$ & $\begin{array}{l}\text { Indicates whether } \\
\text { exterior pressure is } \\
\text { a monotonic }\end{array}$ & $\begin{array}{l}0 \text { (growing); } 1 \\
\text { (fluctuating) }\end{array}$ \\
\hline & threshold $_{c}$ & $1-100$ & $\begin{array}{l}\text { Defines threshold } \\
\text { to be surpassed to } \\
\text { open a window for } \\
\text { reform }\end{array}$ & $20 ; 40 ; 60$ \\
\hline \multirow{3}{*}{ Normative } & $\rho$ & $0-1$ & $\begin{array}{l}\text { Determines the } \\
\text { speed of } \\
\text { professionalisation }\end{array}$ & $0.01 ; 0.1 ; 0.3$ \\
\hline & & & Defines threshold & \\
\hline & threshold $_{n}$ & $1-100$ & $\begin{array}{c}\text { to be surpassed to } \\
\text { open a window for } \\
\text { reform }\end{array}$ & $20 ; 40 ; 60$ \\
\hline \multirow{3}{*}{ Mimetic } & $\omega$ & $0-1$ & $\begin{array}{l}\text { Determines the } \\
\text { initial level of } \\
\text { uncertainty }\end{array}$ & $\begin{array}{c}0 ; 0.25 ; 0.5 \\
0.75\end{array}$ \\
\hline & & & $\begin{array}{c}\text { Defines size of the } \\
\text { vicinity that a }\end{array}$ & \\
\hline & $d$ & $1-4$ & $\begin{array}{c}\text { country consults } \\
\text { before making a } \\
\text { decision }\end{array}$ & $1 ; 2 ; 3 ; 4$ \\
\hline
\end{tabular}

The set of possible values for this set of parameters leads to 2,592 distinct scenarios. Each scenario is repeated 25 times, and we then work with the average of the results. This process brings us to a final number of 64,800 simulations. The duration chosen for each simulation was 30 iterations. Each iteration can be compared to a year. The general form of the adoption curve is logarithmic. In our model, adoption is a process with no possibility of turning back. It is interesting to note that our simulations do not necessarily converge toward an adoption of the norm by all of the agents. The following pseudo-code schematically represents the running of a simulation.

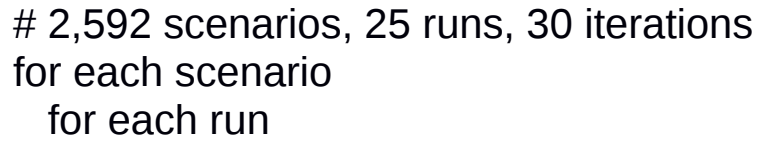




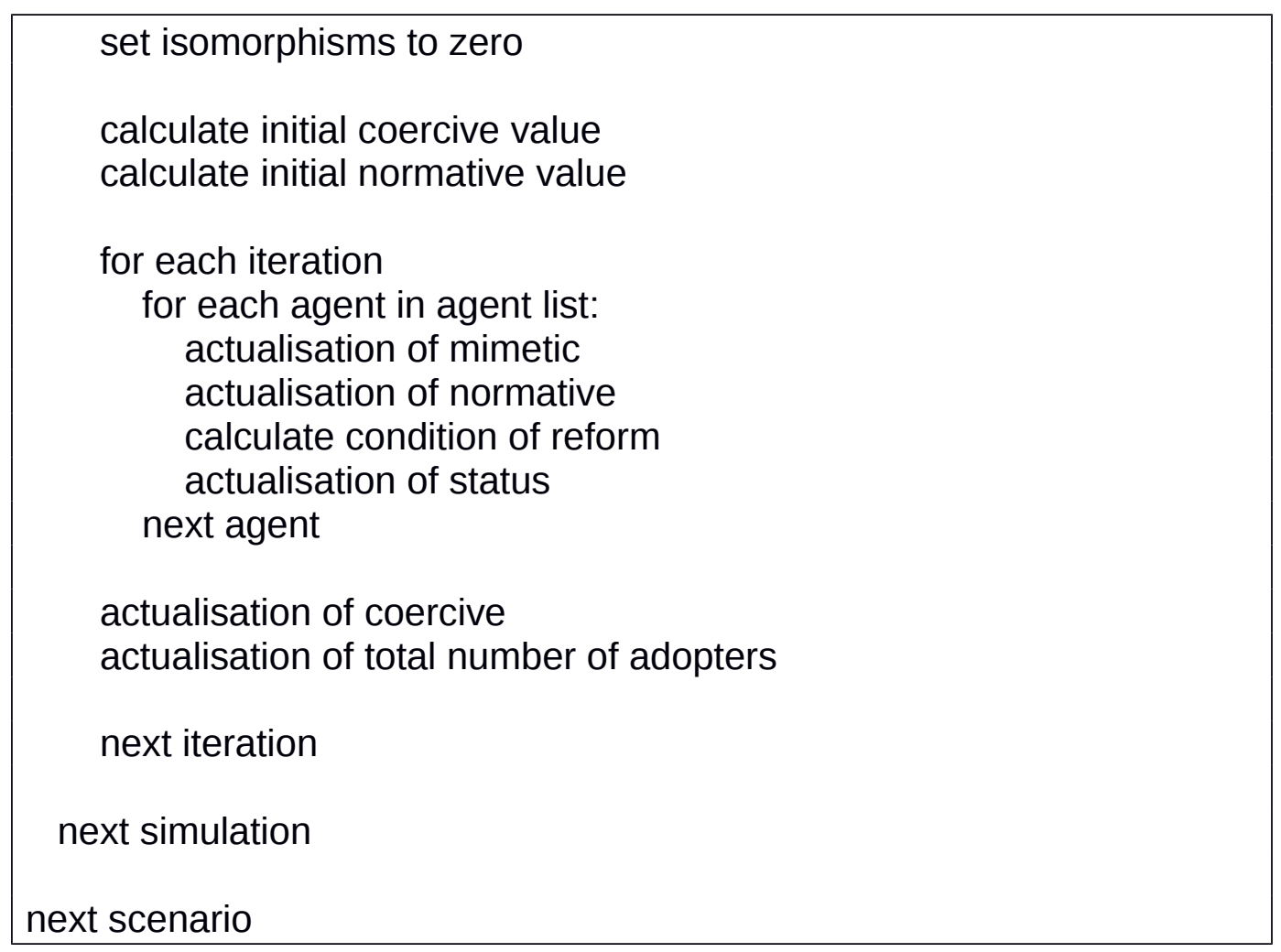

Figure 3: Description of our computer program

The following scenarios result in an almost total adoption of the standard: a coercive force that is uniquely composed of external pressure $\left(i_{\gamma}=1\right)$, elevated speeds of professionalisation ( $\rho$ equal to 0.01 or 0.03 ), and a low normative threshold ( threshold $_{n}=20 \%$ ). In these cases, the simulations result, 19 times out of 20, in all agents adopting the new standards (the $5^{\text {th }}$ percentile is, in fact, equal or very close to the total number of agents, which is 225). 
Table 2: Final number of adopters according to the scenario

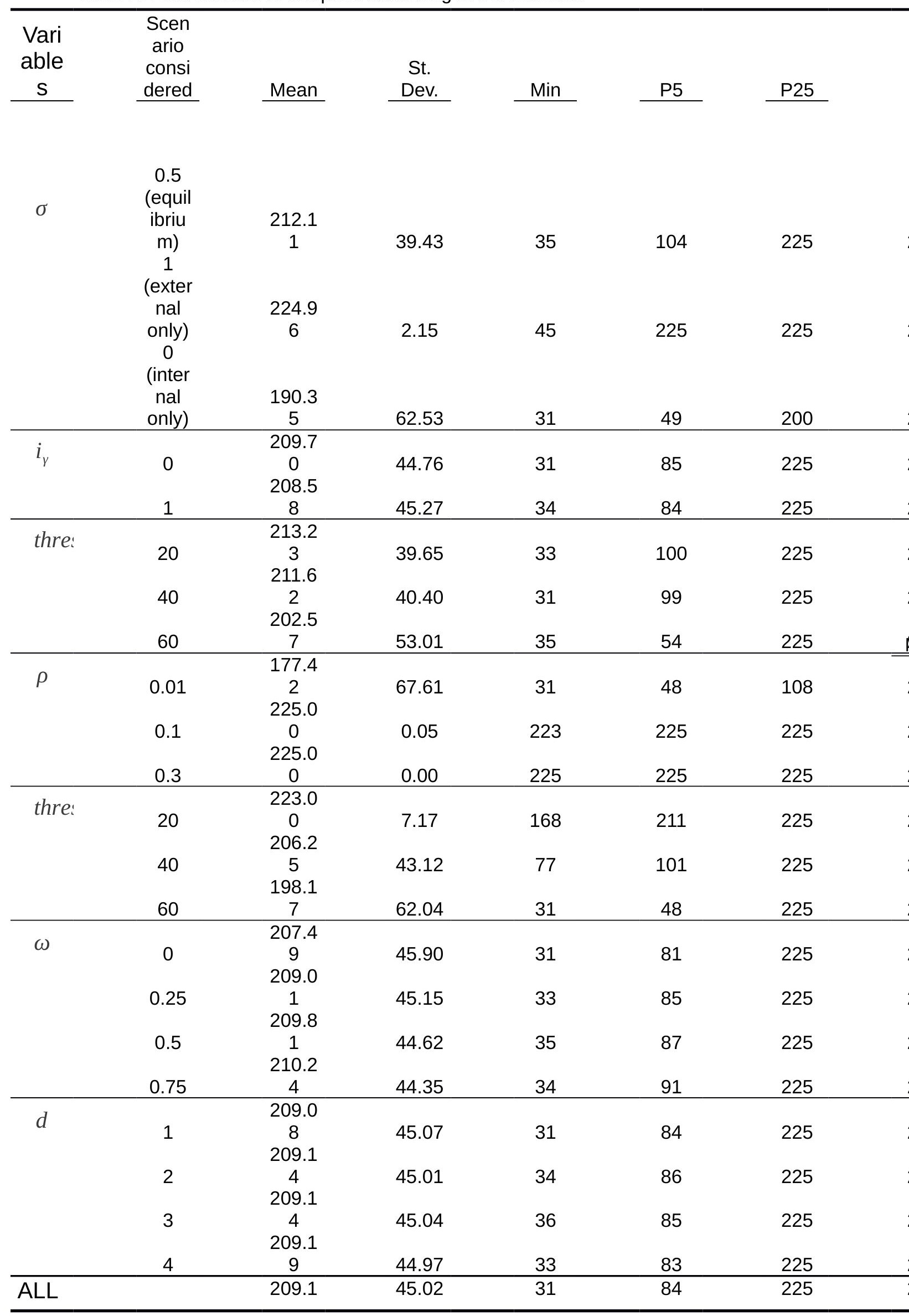




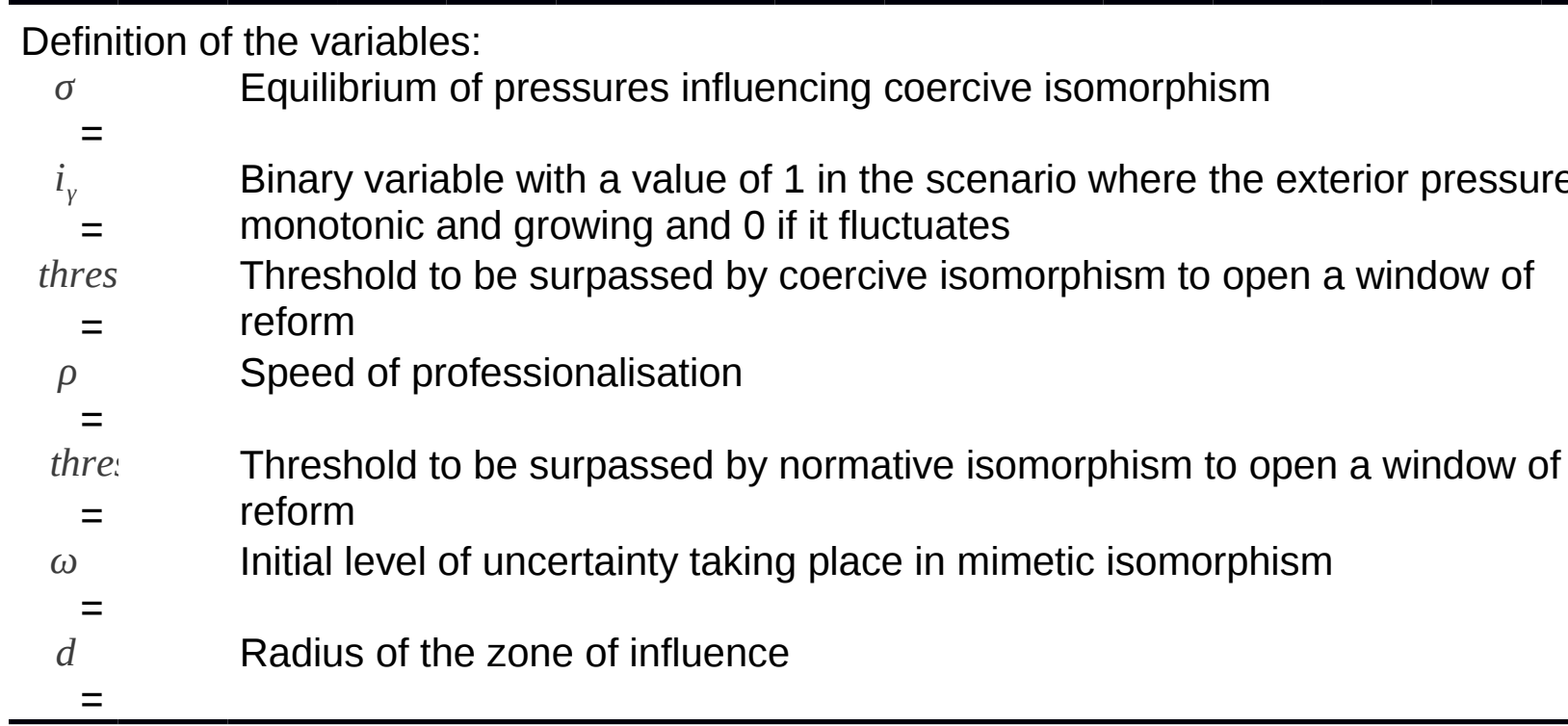

\subsection{Comparison between the generated and the collected data}

The purpose of this section is to compare the result of the simulations and the actual diffusion of the IFRS.

We collected a forecast of motion towards adopting the IFRS by country on the website of IAS plus (www.iasplus.com) (see table 3). The numbers represent the current and collected data for 13 years from 2005 to 2016. 


\begin{tabular}{|c|c|c|c|}
\hline Year & $\mathrm{t}$ & $\begin{array}{c}\text { IFRS } \\
\text { Adopters }\end{array}$ & $\begin{array}{c}\text { Cumulative IFRS } \\
\text { Adopters }\end{array}$ \\
\hline$<2005$ & 1 & 2 & 2 \\
\hline 2005 & 2 & 33 & 35 \\
\hline 2006 & 3 & 3 & 38 \\
\hline 2007 & 4 & 7 & 45 \\
\hline 2008 & 5 & 9 & 54 \\
\hline 2009 & 6 & 9 & 63 \\
\hline 2010 & 7 & 8 & 71 \\
\hline 2011 & 8 & 7 & 78 \\
\hline 2012 & $\begin{array}{l}9 \\
1\end{array}$ & 10 & 88 \\
\hline 2013 & 0 & 1 & 89 \\
\hline 2014 & $\begin{array}{c}11 \\
1\end{array}$ & 1 & 90 \\
\hline 2015 & $\begin{array}{l}2 \\
1\end{array}$ & 1 & 91 \\
\hline 2016 & 3 & 1 & 92 \\
\hline
\end{tabular}

Source: www.iasplus.com/country/useias.htm

For each scenario (thus, each set of parameters), an average of the number of adopters was calculated for the first 13 iterations. The size of the sample then increases to 2,592 (which is the total number of distinct scenarios).

In a first step, we classified the scenarios into two groups with regard to the actual diffusion: group 1, made up of scenarios that are significantly distant from the actual diffusion, and group 2, made up of scenarios close (not significantly distant) to the actual diffusion. This segmentation was performed with the help of a K-S test. If this test is significant, the adoption curve for a simulation differs significantly from the actual adoption curve. At the end of the test, group 1 includes 2,243 scenarios and group 2 includes 349 scenarios.

In a second step, we specify the characteristics of these two groups using tests that compare frequencies. 


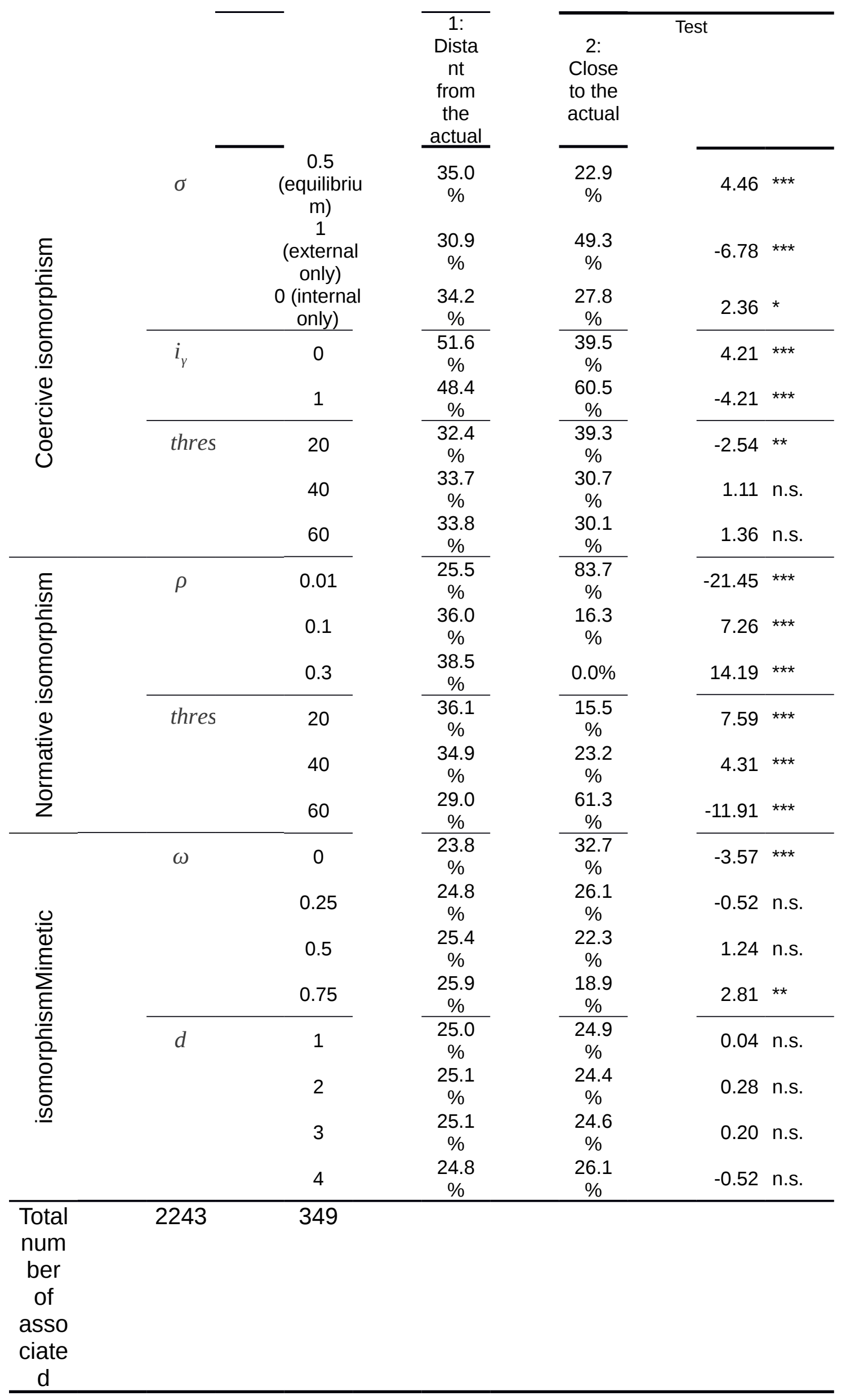




\begin{tabular}{|c|c|}
\hline \multicolumn{2}{|l|}{$\begin{array}{l}\text { scen } \\
\text { arios }\end{array}$} \\
\hline n.s. [no & nificant] $p \geq 0.05 ;{ }^{*} p<0.05 ;{ }^{* *} p<0.01 ;{ }^{* \star *} p<0.001$ \\
\hline \multicolumn{2}{|c|}{ Definition of the variables: } \\
\hline $\begin{array}{c}\sigma \\
=\end{array}$ & Equilibrium of pressures influencing coercive isomorphism \\
\hline$i_{\gamma}$ & $\begin{array}{l}\text { Binary variable with a value of } 1 \text { in the scenario where the } \\
\text { exterior pressure is monotonic and growing and } 0 \text { if it fluctuates }\end{array}$ \\
\hline $\begin{array}{l}\text { thresl } \\
\quad=\end{array}$ & $\begin{array}{l}\text { Threshold to be surpassed by coercive isomorphism to open a } \\
\text { window of reform }\end{array}$ \\
\hline $\begin{array}{l}\rho \\
=\end{array}$ & Speed of professionalisation \\
\hline $\begin{array}{l}\text { thres } \\
\quad=\end{array}$ & $\begin{array}{l}\text { Threshold to be surpassed by normative isomorphism to open a } \\
\text { window of reform }\end{array}$ \\
\hline$\omega=$ & Initial level of uncertainty taking place in mimetic isomorphism \\
\hline${ }^{d}=$ & Radius of the zone of influence \\
\hline
\end{tabular}

Table 4 compares the two groups according to the parameters of the simulation. For each group, the table indicates the percentage of simulations possessing the corresponding value. A test of the comparison of frequencies allows us to elucidate a significant difference between group 1 (simulations whose diffusion curve departs from the real curve) and group 2 (simulations whose diffusion curve is close to the real curve).

The scenarios of group 2 ("close to the actual data") are characterised - in comparison to the scenarios of group 1 - by:

- higher weighting associated with the environment within coercive isomorphism, $\square=1$;

strong intensity of pressure from the environment, $i_{\gamma}=1$, within coercive isomorphism;

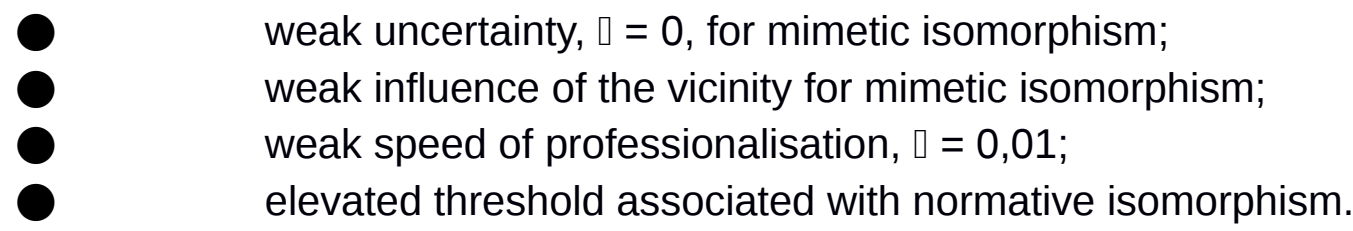

The two most significant isomorphisms in the simulation are the coercive and the normative isomorphisms. If one leaves aside the threshold $c$ parameter for the four other parameters, that is $\square, i_{\gamma}, \square$, and threshold $_{n}$, the differences in the frequencies between the two groups are always statistically significant.

For coercive isomorphism, group 2 is characterised by the greater role of the environment and by a weak threshold of adoption. For 
normative isomorphism, group 2 is characterised by a weak speed of professionalisation and by an elevated threshold of adoption. For the frequencies test, the two parameters that are associated with the highest $z$ test statistics are $\square$ and threshold ${ }_{n}$, which intervene in the parameters for normative isomorphism.

This result shows that the choice of simulation tools, equations, threshold, and probability allowed a result that has already been proposed within the framework of analysis of adoption: the crucial role played by external pressures - coercive and normative isomorphisms - experienced by states (Mir and Rahaman, 2005, Chand and Patel, 2008, Irvine, 2008, Albu et al., 2011, and Lasmin, 2011).

\section{Conclusion}

The goal of this study was to elaborate a model using the conceptual framework of DiMaggio and Powell that allows for a numerical multi-agent simulation to be implemented that models the diffusion of the IFRS. This model led us to formalise and quantify the isomorphic forces defined in this conceptual framework.

We believe that this goal responds to a need because the DiMaggio and Powell grid is frequently used to analyse the mechanisms of adoption of new accounting practices and standards.

The studies using this framework are limited to the static study of adoption. The proposed model allowed us to represent the dynamics of the diffusion of the new IFRS. Our model allows, under certain conditions of calibration, a simulation of the diffusion that is close to the observed diffusion. In this case, the isomorphisms that play a decisive role are the same as those highlighted in earlier studies.

One possible development of our study would be the implementation of this model in a different area. A second path would be to develop this model to use it for predictive purposes. 
References

Albu, N., Albu, C. N., Bunea, S., Calu, D. A., \& Girbina, M. M. (2011). A story about IAS/IFRS implementation in Romania. Journal of Accounting in Emerging Economies, 1(1), 76-100.

Baker, R. O. N., \& Rennie, M. D. (2006). Forces Leading to the Adoption of Accrual Accounting by the Canadian Federal Government: An Institutional Perspective. Canadian Accounting Perspectives, 5(1), 83-112, doi:10.1506/206k-rv7l-2jmn-w3d3.

Caccia, L., \& Steccolini, I. (2006). Accounting change in Italian local governments: What's beyond managerial fashion? Critical Perspectives on Accounting, 17(2-3), 154-174, doi:10.1016/j.cpa.2003.05.004.

Carpenter, V. L., \& Feroz, E. H. (2001). Institutional theory and accounting rule choice: an analysis of four US state governments' decisions to adopt generally accepted accounting principles. Accounting, Organizations and Society, 26(7-8), 565-596, doi:10.1016/s03613682(00)00038-6.

Chand, P., \& Patel, C. (2008). Convergence and harmonization of accounting standards in the South Pacific region. Advances in Accounting, 24(1), 83-92, doi:10.1016/j.adiac.2008.05.002.

Chiapello, E., \& Medjad, K. (2009). An unprecedented privatisation of mandatory standard-setting: The case of European accounting policy. Critical Perspectives on Accounting, 20(4), 448-468, doi:10.1016/j.cpa.2008.09.002.

Chua, W. F., \& Taylor, S. L. (2008). The rise and rise of IFRS: An examination of IFRS diffusion. Journal of Accounting and Public Policy, 27(6), 462-473, doi:10.1016/j.jaccpubpol.2008.09.004.

Collin, S.-O. Y., Tagesson, T., Andersson, A., Cato, J., \& Hansson, K. (2009). Explaining the choice of accounting standards in municipal corporations: Positive accounting theory and institutional theory as competitive or concurrent theories. Critical Perspectives on Accounting, 20(2), 141-174, doi:10.1016/j.cpa.2008.09.003.

Davis, J. P., Eisenhardt, K. M., \& Bingham, C. B. (2007). Developing theory through simulation methods. The Academy of Management Review ARCHIVE, 32(2), 480-499.

DiMaggio, P. J., \& Powell, W. W. (1983). The Iron Cage Revisited: Institutional Isomorphism and Collective Rationality in Organizational Fields. [Article]. American Sociological Review, 48(2), 147-160.

Eisenhardt, K. M. (1989). Building theories from case study research. Academy of Management Review, 532-550.

Freese, L. (1980). Formal theorizing. Annual Review of Sociology, 6, 187212.

Hawley, A. (1968). Human ecology. In D. L. Sills (Ed.), International Encyclopedia of the Social Sciences (pp. 328-337). New York: Macmillan.

Hoque, Z., \& Adams, C. (2011). The Rise And Use Of Balanced Scorecard Measures In Australian Government Department. Financial Accountability \& Management, 27(3), 308-334, doi:10.1111/j.14680408.2011.00527.x. 
Irvine, $\mathrm{H}$. (2008). The global institutionalization of financial reporting: The case of the United Arab Emirates. Accounting Forum, 32(2), 125142, doi:10.1016/j.accfor.2007.12.003.

Järvinen, J. (2006). Institutional Pressures for Adopting New Cost Accounting Systems in Finnish Hospitals: Two Longitudinal Case Studies. Financial Accountability \& Management, 22(1), 21-46, doi:10.1111/j.0267-4424.2006.00391.x.

Judge, W., Li, S., \& Pinsker, R. (2010). National Adoption of International Accounting Standards: An Institutional Perspective. Corporate Governance: An International Review, 18(3), 161-174, doi:10.1111/j.1467-8683.2010.00798.x.

Lasmin, D. (2011). An Institutional Perspective on International Financial Reporting Standards Adoption in Developing Countries. Academy of Accounting and Financial Studies Journal, 15(2).

Mir, M. Z., \& Rahaman, A. S. (2005). The adoption of international accounting standards in Bangladesh: An exploration of rationale and process. Accounting, Auditing \& Accountability Journal, 18(6), 816-841.

Pfeffer, J. (1993). Barriers to the advance of organizational science: Paradigm development as a dependent variable. Academy of Management Review, 599-620.

Rand, W., \& Rust, R. T. (2011). Agent-based modeling in marketing: Guidelines for rigor. International Journal of Research in Marketing, 28(3), 181-193, doi:10.1016/j.ijresmar.2011.04.002.

Touron, P. (2005). The adoption of US GAAP by French firms before the creation of the International Accounting Standard Committee: an institutional explanation. Critical Perspectives on Accounting, 16(6), 851-873, doi:10.1016/j.cpa.2003.08.011.

Tsamenyi, M., Cullen, J., \& González, J. M. G. (2006). Changes in accounting and financial information system in a Spanish electricity company: A new institutional theory analysis. Management Accounting Research, 17(4), 409-432, doi:10.1016/j.mar.2006.02.002.

Wang, J., Gwebu, K., Shanker, M., \& Troutt, M. D. (2009). An application of agent-based simulation to knowledge sharing. Decision Support Systems, 46(2), 532-541, doi:10.1016/j.dss.2008.09.006. 